\title{
The effect of race and gender on attributions of stalking.
}

\section{Simon C. Duff, University of Nottingham}

\section{Jonathan Hay, University of Nottingham}

Jessica Kerry, University of Nottingham

\section{Alyssa Whittam, University of Nottingham}

\begin{abstract}
Objective: This study is concerned with examining the impact of the extra-legal factors of race and gender in attributions of stalking and motivation in examples of heterosexual, low-level stalking behaviour.

Methods: A 4 (race pairing of protagonist and target) x 2 (gender pairing of protagonist and target) between participants design, using a vignette incorporating faces of the protagonist and target, asked participants to identify the extent to which they considered the behaviour stalking, the motivation for that behaviour, and provide responses to measures of racism and sexism.

Results: The results identify that intra-racial behaviour is considered more like stalking than inter-racial behaviour, that female-to-male behaviour is considered more like stalking than male-to-female and that gender and race do not impact on the attributed motivations for the behaviour. Both racism and sexism do contribute to attributions of stalking.

Conclusion: The influence of race on attributions of stalking mirrors that of findings in other areas of crime and is important in understanding decision making.
\end{abstract}

\section{INTRODUCTION}

Stalking research concerned with public attributions of threat of violence or target guilt, for example, has shown that there are biases impacting our decision making. Studies have demonstrated that stranger stalkers are routinely attributed to be more concerning than ex-partner stalkers (Weller, Hope, \& Sheridan, 2013) and male stalkers more concerning than female stalkers (Scott, Rajakaruna, Sheridan, \& Gavin, 2015). The presence of these biases is more than simply academic as they may play a role in important decisions away from the laboratory; the belief that expartner stalkers are not a threat and are less likely to be stalking may result in targets of this kind of behaviour not understanding the risk; family, friends, and other sources of support equally downplaying it (Pearce \& Easteal, 1999); the police dismissing it (Scott, Nixon, \& Sheridan, 2013) and, if it were to reach court, being minimised by a jury (Scott \& Gavin, 2011, Duff et al., in press). As such it is of applied value to map the geography of these attributional biases. As more attention is paid to attributional bias in stalking the questions posed are moving away 
from what we might consider the typical stalking scenario, where a white male stalks a white female. Useful insights regarding our biases have been identified by researchers such as Scott and colleagues (2015) who examined the influence of reversing the gender pairing of target and stalker, and Sheridan, North, and Scott (2014) who studied the impact of same-sex pairings in self-defined targets of stalking, as did Scott and Tse (2011) in an empirical study. However, to date the impact of race has rarely been explored in such studies. That race may play an important part in attributions of stalking is borne out by research in psychology that demonstrates racial biases. The present study contributes to research on perceptions of stalking by examining the impact of race and gender on attributions and perceived motivations of stalking in heterosexual, stranger stalking.

\section{Race}

Various psychological studies have demonstrated an impact of race. Payne (2001) used a priming method to investigate the effect that a Black or White face has on participants' ability to identify objects. The study recruited male and female non-Black participants. It was found that the presence of a Black prime caused participants to misidentify objects as weapons whereas with White primes participants identified non-threatening objects. This is non-trivial as Correll and colleagues (2002) examined how race and presence of a weapon would impact upon a US community sample's decisions to shoot or not shoot an individual depicted in a video game. They found that White participants were faster at deciding to shoot an armed Black person than an armed White person and were quicker to decide not to shoot an unarmed White person than an unarmed Black person, and this effect was shown to be independent of individual racial prejudice. A later study (Correll et al., 2007) found similar results in a sample of US police officers. Lantz, Gladfelter, and Ruback (2017) examined hate crimes in the US and suggest that the police react to stereotypes of hate crimes (White offenders, Black victims) rather than the specifics of the crime, thus racial and crime stereotypes appear to exist for different races and different offending behaviour.

Examining more general biases of criminality Madriz (1997) carried out focus groups and interviews with American women $(n=140)$ to explore their fear of crime. One of her findings was that irrespective of the race or socioeconomic status of her participants, women most feared Black and Latino men to be criminal. Similar findings have been reported by Valentine (1989), Steffensmeier et al. (1998), and Day (1999). Madriz also reports that her sample considered that White women were more likely to be victims of crime in general. Further evidence that race plays an important role in aspects of thinking and decision making in relation to crime. 


\section{Juries and race}

George and Martinez (2002) found that interracial rapes are judged less like rape, the victims are judged to be less believable and to be more culpable when compared to intra-racial rapes, as deliberated by juries. Ugwuegbu (1979) showed that in a simulated case of rape both victim race and defendant race influenced levels of guilt assigned to the defendant, with a defendant considered more culpable, regardless of race, if he was of a different race to the jurors. Sommers and Elsworth (2000) identified an impact of defendant race in mock juror studies, where White jurors considered a Black defendant to be more aggressive, violent, and guilty than a White defendant, but only when racial issues were not highlighted in the case. However, Black jurors demonstrated a bias in favour of Black defendants. Dixon, Mahoney, and Cocks (2002) showed that race interacted with accent and crime type to increase attributions of guilt when a defendant presented as non-White, from Birmingham (UK), and having committed armed robbery. However, a 2010 Ministry of Justice Study (Thomas, 2010) using data from all Crown Court cases in England and Wales between 2006 and $2008(n=66,889)$ suggested that real jury verdicts show different conviction rates for race dependent on the offence type (for example, in cases identified as 'falsification' the conviction rate for White defendants is $66 \%$ and for Black and Minority Ethnic (BME) defendants it is $77 \%$; in cases identified as 'homicide' the conviction rate for White defendants is $57 \%$ and for BME defendants it is $51 \%$ ). Overall Thomas concluded that there were no systematic effects of race on jury decisions. Of course, in these cases we do not know the demographics of the jury nor do we know how race may play a role in the deliberation of mixed-race juries.

One possible explanation for the apparent inconsistencies in how crime and race appear to be understood has been offered by Hurwitz and Peffley (1997). They suggest that it is not the case that one's racial stereotypes will be recruited in decision making across all crime types and all situations, but rather only when a particular crime fits with that stereotype (as the work of Lantz, Gladfelter, and Ruback (2017) indicates). To support this idea they cite Hacker's (1995) view, “Quite clearly, 'Black crime’ does not make people think about tax evasion or embezzling from brokerage firms. Rather the offenses generally associated with Blacks are those...involving violence...” (p. 188), which is explicit about the idea that attributes regarding aspects of criminality can be biased by race. As yet it is not clear if the crime of stalking fits with a particular racial stereotype. 


\section{Stalking and race}

Kinkade, Burns, and Fuentes (2005) examined perpetrator race as one of the factors in their study of undergraduate students concerned with perceptions of stalkers and found no effect, in relation to either stalkers or their targets.

However, their manipulation consisted of adding in the descriptor 'Black' to some of their conditions, which assumes that where no racial descriptor is included participants would have perceived the perpetrator as White. This may be true as $83.7 \%$ of their sample of 356 University students described themselves as Caucasian and there may be a tendency towards intra-racial stereotyping for perpetrators of stalking. The fact that $40.2 \%$ of the sample described that they had an experience of stalking (themselves or a friend) may suggest, given Bjerregaard's (2002) findings that stalking is multi-racial, that this assumption may not be entirely safe. Bjerregaard (2002) reports that in her sample of US University students $24.6 \%$ of stalked women described themselves as non-White and $32.1 \%$ of stalked women described their stalker as non-White. $27.6 \%$ of male targets described themselves as non-White and 18.5\% of male targets describe their stalker as non-White. The 2010 National Intimate Partner and Sexual Violence Survey found that for the estimated lifetime prevalence of stalked women $(n=19,327,000)$ in the US approximately $14 \%$ described themselves as Black and for the men $(n=5,863,000)$ approximately $13 \%$ described themselves as Black (Black, Basile, Breiding, Smith, Walters, Merrick, Chen, \& Stevens, 2011). Studies have been inconclusive as to whether race is a risk factor for violence in stalking (Rosenfeld, 2004), similarly with prevalence where some studies suggest that non-Whites have a higher risk of experiencing stalking (Baum, Catalano, Rand, \& Rose, 2009) whereas other studies suggest that White individuals are more likely to be victimized (e.g. Bjerregaard, 2002). Race has also been considered with respect to fear in targets with Dietz and Martin (2007) reporting that Black women reported experiencing less fear than White women during an experience of stalking.

Research suggests that race can play a role in attributions and behaviours linked to criminal behaviour; in relation to stalking it is yet to be fully considered. This is an important question beyond simply biases in perceptions of stalking, it responds to the recent suggestion that psychology should attempt to understand and contribute to the potential negative impact of racial and ethnic bias (Mays et al., 2013) and Sheridan, Blaauw, and Davies' (2003) view that we should not consider stalkers and stalking as homogenous but rather should pay attention to different subgroups. 


\section{Perpetrator-Target Gender}

Results from research concerned with the impact of gender on stalking attributions is inconclusive. Scott, Duff, Sheridan, and Rajakaruna (2018) found that stalking by a male against a female is considered more serious and is more likely to result in fear of violence than the same behaviours by a woman against a man. This supports previous findings (e.g. Cass \& Mallicoat, 2015; Podaná \& Imríšková, 2016; Sheridan \& Scott, 2010) and statistics that report more prosecutions for female targets than male (Lyndon et al., 2012), but contradicts other findings that suggest there is no gender difference (e.g. Sheridan, North, \& Scott, 2014; Strand \& McEwan, 2012). As Madriz (1997) has identified that women fear Black men it is important to examine the extent to which attributions of stalking are due to gender, race, or a combination. Additionally it is likely that the attributions of motivation that are identified for a person's behaviour are linked to the extent to which one sees a behaviour as more or less benign and one's biases regarding race and gender.

\section{Present study}

To date there are no studies that have examined general public attributions of stalking and its motivations, when the race and gender of the perpetrator and target have been systematically varied in heterosexual pairs. Where race of the perpetrator has been varied, as in the Kinkade et al. study (2005), it has been done by applying the label Black, assuming that the non-labelled conditions will be attributed to White people. The current study explores the two extra-legal factors of gender and race. Race is manipulated by presenting Black or White faces (as per Payne, 2001) with vignette descriptions, gender is manipulated by these faces being male or female and by the names used for the protagonist and target. The aim is to examine if race and gender pairing influence participants' attributions of stalking and the attributed motivation for that stalking. Additionally measures of sexism and racism are examined for their contribution to participants' responses. The hypotheses for this study were as follows;

1. Both sexism and racism will contribute to the extent to which behaviour is considered to be stalking.

2. Intra-racial behaviour will be identified as more like stalking than interracial behaviour.

3. Male behaviour towards a female will be identified as more like stalking than the same behaviour by a female towards a male.

4. Female perpetrator motivations will be considered more benign than male perpetrator motivations.

5. Interracial motivations will be considered more benign than intra-racial motivations. 


\section{METHOD}

\section{Design}

This study replicates the method of Scott et al. (2018) in measuring attributions of stalking based on vignettes of low-level stalking. In addition it employs a 4x2 (protagonist-target racial pairing x protagonist-target gender composition), between-participants design manipulating the race of the protagonist and the target and the gender of the protagonist and the target. Participants were asked to what extent the described behaviour constitutes stalking and to state what they believed the motivation of the protagonist was. Next, participants responded to the subscales of the Intolerant Schema Measure (ISM; Aosved, Long, \& Voller, 2009) to account for racism and sexism in the sample. Examples of racism items include responses to the following statements using a 5-point Likert-type scale (1 $=$ strongly disagree to $5=$ strongly agree); "Racial minorities are getting too demanding in their push for equal rights" and "It is a bad idea for racial minorities and Whites to marry one another". Examples of sexism items include responses to the following statements using a 5-point Likert-type scale $(1=$ strongly disagree to $5=$ strongly agree); "The intellectual leadership of a community should be largely in the hands of men" and "Women should worry less about their rights and more about becoming good wives and mothers". Finally participants provided demographic information. The study received ethical approval from the Medical Faculty's ethics committee of a UK Russell Group University, which complies with the Declaration of Helsinki, and was informed by the British Psychological Society’s Ethics Guidelines for Internet-mediated Research (BPS, 2017).

\section{Power analysis}

A power analysis was conducted using G*Power 3 (Faul, Erdfelder, Lang, \& Buchner, 2007). For a medium effect size $(\mathrm{f}=.25)$, power of .8 , alpha of .05 for an ANCOVA with 2 covariates the total sample size required was calculated as $270($ Critical $\mathrm{F}=1.87)$.

\section{Participants}

607 members of the general public were recruited online (184 males, 416 females, 7 identified as non-binary (2 agender; 2 non-binary; 3 transgender), aged between 18 and 72 (Mean =32.4, SD=14.31), the majority selfidentifying as White $(n=484,80 \%)$ and heterosexual $(n=513,85 \%) .34 \%$ reported having an undergraduate degree, suggesting, based on the mean age, that the sample is not predominantly a student population and, according to the Office for National Statistics, the percentage of participants with an undergraduate degree is somewhat lower than the percent of the UK population who have achieved higher education qualifications (42\%; ONS, 2017). 


\section{Materials}

The study was constructed within the Qualtrics online environment (https://www.qualtrics.com/uk/edu/). The experimental stimuli were an image of a black man, an image of a white man, an image of a white woman, and the image of a black woman (see Figure 1 for examples) that were designed using face creation software (Poser; https://my.smithmicro.com/poser-pro-11.html). The images of the men were identical to each other as were the images of the women, other than the colour of the face. The men were given the name Michael, and the women Sarah. All images had a neutral facial expression and measured $30 \mathrm{~mm}$ in width by $30 \mathrm{~mm}$ in height. The images were designed in this manner so that only the skin colour and gender of the image might influence a participant's judgement.

\section{Figure 1 about here please}

A demographic questionnaire was designed to collect basic information. A vignette (see below), similar to those used in previous studies (Duff et al., in press; Scott et al., 2018) with one person, either a Black or White man or woman, displaying low-level stalking-like behaviour towards a Black or White woman or man, always presented as heterosexual pairings.

\section{An example vignette}

A woman, Sarah has recently been stopped in the street of a major city and spoken to a few times over the last two weeks by a man, Michael, who has also been leaving messages and small gifts for her at her work place. Sarah has noticed Michael quite often at places that she goes to, like the supermarket, a coffee shop, and the gym, both when she is on her own and when she is with her current partner. Sarah has also seen Michael coming out of a flat that is quite close to hers.

An 11-point Likert-type scale regarding the extent to which participants identified the behaviour as stalking was designed, based on previous work (e.g. Duff \& Scott, 2013), along with a single-choice list of 6 possibilities as to the most likely attributed motivation for the behaviour. These motivations were based on the typologies of stalking as suggested by Meloy (2013) and that are used in the Stalking Risk Profile (SRP), a structured professional judgement tool for managing risk (see MacKenzie, McEwan, Pathé, James, Ogloff, \& Mullen, 2009). The 18, 5point Likert-type scale items (ranging from $1=$ strongly disagree to $5=$ strongly agree) from the Intolerant Schema Measure (ISM) (Aosved, Long \& Voller, 2009) that measure levels of racism (9 items) and sexism (9 items) were 
used to examine the effects of these factors on responses. These subscales are reported to have good internal consistency. For racism Aosved et al., (2009) report good internal consistency (Chronbach's $\alpha .81$ ), criterion validity, and test-retest reliability $(r=.86)$ and for sexism they report good internal consistency (Chronbach's $\alpha$ $.82)$, criterion validity, and test-retest reliability $(\mathrm{r}=.85)$. Subscale scores are calculated from the average of the nine items, higher scores indicative of higher levels of intolerance (Aosved et al., 2009).

\section{PROCEDURE}

Potential participants accessed an internet link where they were presented with an information sheet explaining that the experiment would be about people's perceptions to a given social situation and were asked to confirm that they were older than 18 years and to consent to participate. Demographic information was collected (age, gender, sexual orientation, ethnicity, and education) and participants were then randomly assigned to one of the eight conditions;

1. Michael (white male protagonist) Sarah (white female target).

2. Michael (white male protagonist) Sarah (black female target).

3. Michael (black male protagonist) Sarah (white female target).

4. Michael (black male protagonist) Sarah (black female target).

5. Sarah (white female protagonist) Michael (white male target).

6. Sarah (black female protagonist) Michael (white male target).

7. Sarah (white female protagonist) Michael (black male target).

8. Sarah (black female protagonist) Michael (black male target).

The vignette provided the appropriate names and genders for the given condition, with the relevant faces provided, with the protagonist's face presented on the left and the targets on the right. Other than gender the vignette text was identical across conditions. Participants were then presented with the question regarding how much they considered the behaviour to be an example of stalking and then why they believed the protagonist had behaved in such a manner towards the target, with six options to choose from that described a desire by the protagonist to either humiliate, win back, form a relationship with, date, or assault the target, the last option being that the protagonist is not stalking the target. The final part of the experiment required participants to complete subscales of Aosved et al's (2009) ISM. For this, participants were given 18 statements and were required to rate their agreement or disagreement to each. Once participants completed this stage they were asked once again for their consent for their data being used and stored. No personally identifying information was gathered from participants nor were IP 
numbers collected or stored by the software, thus ensuring the privacy and anonymity of the participants.

Participants were then debriefed, told the true purpose of the study, and given information if they felt affected by the focus on stalking.

\section{RESULTS}

The data were initially screened for errors and normality. The data did not meet the assumptions for parametric analysis and these could not be corrected through transformation so non-parametric analyses have been employed throughout.

\section{Attributions of stalking}

Table 1 provides the group data providing means and for the extent to which the behaviour was considered stalking, along with means and for sexism and racism.

\section{Table 1 about here please}

In order to examine the potential impact of the covariates sexism and racism (hypothesis one) Quade's (1967) nonparametric approach was used, based on ANOVA of the unstandardized residuals calculated from linear regression of the rank orderings of the stalking, sexism, and racism scores. This showed that both racism $(\mathrm{F}(7,599)=2.81$, $\mathrm{p}<.01, \mathrm{r}=.03)$ and sexism $(\mathrm{F}(7,599)=2.62, \mathrm{p}<.05, \mathrm{r}=.03)$ do contribute to stalking attribution scores in this study.

Independent Kruskal-Wallis tests were performed on the responses to the stalking question and the scores for the racism and sexism measures. There were no group differences for either racism or sexism, however the groups differed significantly on the extent to which they identified the behaviour as stalking (Chi-Square $=16.4, \mathrm{df}=7$, $\mathrm{p}<.05)$

In order address hypothesis two (that intra-racial behaviour will be identified as more like stalking than interracial behaviour) and to avoid inflating the Type I error rate by comparing all group pairings the analytic strategy taken was to combine groups and compare the group which exemplified intra-racial stalking to that which exemplified interracial stalking, ignoring gender, using Wilcoxon's rank-sum test. This comparison showed groups responding to exemplars of intra-racial stalking ( $\mathrm{Mdn}=7$, Mean $=6.35$ ) rated it as more like stalking than those responding to exemplars of interracial stalking $\left(\mathrm{Mdn}=6\right.$, Mean $\left.=5.98, \mathrm{~W}_{\mathrm{s}}=81312, \mathrm{p}<.01, \mathrm{r}=.19\right) .2$ Mann-Whitney tests compared within these groups, using a Bonferroni corrected value of $\mathrm{p}=.025$. There was no difference between 
either of the two interracial groups (i.e. White : Black vs. Black : White, $U=10046, p=.79$ ) or the two intra-racial groups (i.e. Black : Black vs. White : White, $U=10386, \mathrm{p}=.027$ ).

To examine hypothesis three (male behaviour towards a female will be identified as more like stalking than the same behaviour by a female towards a male), again being mindful of inflating Type I errors, a similar strategy was used, combining groups with a male protagonist to compare with those with a female protagonist, examined by Wilcoxon's rank-sum test. This comparison showed groups with a male protagonist $(\mathrm{Mdn}=7$, Mean $=6.05)$ were rated as less like stalking than those experiencing a female protagonist $\left(\mathrm{Mdn}=7\right.$, Mean 6.22, $\mathrm{W}_{\mathrm{s}}=38781, \mathrm{p}<.01$, $\mathrm{r}=.87)$.

\section{Motivations for stalking}

Table 2 provides the data for participants' judgements of motivation, split by group.

\section{Table 2 about here please}

The majority of participants, regardless of gender or race of the protagonist, identified the most likely motivation to either be that the protagonist wants a date or that s/he is lonely and wants to have a relationship, with only $13 \%$ suggesting that the behaviour was not stalking. To examine hypothesis four (female perpetrator motivations will be considered more benign than male perpetrator motivations), based on previous research findings that males' behaviour towards females is considered more concerning than that of females towards males, and the assumption that at least part of this is due to motivations attributed to behaviour, the data were collapsed by gender and if a motivation was considered benign or not. The non-benign motivations were humiliation and assault. There was no significant association between the valence of attributed motivation and gender of the protagonist $\left(\chi^{2}(1)=2.58\right.$, $\mathrm{p}>.05$ ) and neither was there a significant association between identified motivation and gender of the protagonist overall, regardless of valence $\left(\chi^{2}(5)=10.95, \mathrm{p}>.05\right)$. These results suggest that the attributed motivation of the protagonist's behaviour in this study, whether based on the valence of the motivation or not, was not influenced by the gender of the protagonist.

A similar test was performed for the data collapsed by race (same race vs different race of protagonist and target) and valence of the motivation in order to examine hypotheses five (interracial motivations will be considered more benign than intra-racial motivations). Chi-square analysis could be completed using the non-benign motivations despite the expected frequencies of less than 5 as the chi-square test has been shown to give accurate Type I error 
probability statements when expected frequencies are low and $\mathrm{N}$ is greater than 20 (Camilli \& Hopkins, 1978). There was no significant association between identified motivation and gender of the protagonist $\left(\chi^{2}(1)=1.64\right.$, p>.05) where the valence of the motivation (benign vs non-benign) was considered nor overall $\left(\chi^{2}(5)=4.86\right.$, $\mathrm{p}>.05)$. These results suggest that that there are no differences in attributed motivation comparing intra- and interracial pairings.

\section{DISCUSSION}

Before considering the data it is important to acknowledge the possibility of the results being marginalised by socially desirable responding (SDR). Although the participants did not know the purpose of the study until the end some may have believed that they did, whether correctly or not, and this may have influenced their responses. Previous research has shown that very few studies test for SDR yet in those that do $43 \%$ found evidence of SDR (van de Mortel, 2008). The implications for this study is that it is plausible that the results under-represent racial differences in attributions of stalking, however this cannot be assumed and is essential to be explored in further research.

Due to the nature of the data parametric analyses would have been inappropriate however, they would have allowed for a more elegant and nuanced exploration of the data without the concerns of inflating error rates. As such here we are unable, for example, to examine the impact of participant gender and race, without the risk of inflating error rates, which may well play a part in attributions of stalking and identifying motivations for it, and are both important factors to consider. Despite that concern there are some important findings that should motivate further examination and consideration of the influence race has on responses to stalking-like behaviour. The fact that racism and sexism have been shown to contribute to attributions of stalking has implications for understanding both previous research and individual risk. As little previous research has considered the contributions of racism and sexism to studies of stalking we likely have a simplified understanding of the complex processes involved in the judgements made about behaviour (i.e. what 'kind' of behaviour it is; is it concerning, benign, indicative of escalation) and thus how it should be responded to. Studies typically examine the extent to which participants believe that the behaviour needs to be reported to the authorities (Duff \& Scott, 2013) and this has been linked to the extent to which the behaviour is considered to be stalking. It is plausible that racism and sexism also contribute to these decisions. Just as sexism and racism may contribute to decisions about the potential stalking of others it may impact on our own decisions regarding behaviour that we are experiencing. For example, if we become less 
worried about behaviour due to our sexist and racist views we may place ourselves at greater risk. For example, if a White male is less likely to construe behaviour as stalking when acted by a Black female because he believes that females and Black people are less likely to either stalk at all or to stalk White males, he may ignore it or inadvertently escalate the issue by engaging with the individual in some way. A similar effect is demonstrated by the bias evidenced in favour of ex-partners who stalk compared to strangers who behave in the same way (Scott, Nixon, \& Sheridan, 2013); ex-partner stalking behaviour is considered less risky and less like stalking. Similarly, the possible impact of sexism and race on the decisions of juries where there may be important influences on individual decisions, deliberations, and group decision making that result in convictions or acquittals.

Although the impact of racism and sexism cannot be partialled out due to the nature of the available analyses here, as with previous studies concerned with other forms of offending behaviour, such as rape (George and Martinez, 2002) the results here find that intra-racial behaviour is considered to be more like stalking than interracial behaviour. Despite being statistically significant it is important to identify that the actual differences are small and the extent to which these difference may result in real world effects is uncertain. However, it is important to consider explanations for this. The means for the racial pairings show that White-on-White behaviour is considered most like stalking, White-on-Black least $(\mathrm{W}: \mathrm{W}=6.75, \mathrm{~B}: \mathrm{W}=6.07, \mathrm{~B}: \mathrm{B}=5.94, \mathrm{~W}: \mathrm{B}=5.83)$. Theories of group dynamics, such as Tajfel's minimal group paradigm (Tajfel, 1981), would suggest that the in-group, which here would be assumed to be race, would be favoured and as Brewer (1999) states, "positive emotions such as admiration, sympathy, and trust are reserved for the in-group and withheld from the out-group" (p. 438). As such we would expect that with a predominantly White sample, here in-group behaviour towards an out-group would be trusted and thus seen as more benign, thus a White protagonist and a Black target would be considered less an exemplar of stalking by a White sample. Where White-on-White behaviour is perceived more negatively this simple in-group/out-group definition is not useful. However, Turner (1982) has proposed a model, Referent Informational Influence, suggesting that when one's own behaviour differs from the observable behaviour of other in-group members, and when that comparison undermines the positive features of being a group member one may psychologically dissociate from that group and one's own behaviour is considered more normative. In this study, if individuals consider that the behaviour described in the vignette is not typical of them there may be a tendency to criticise more and perceive it as more unusual and concerning, than behaviour involving either an outgroup protagonist or target. The opportunity to examine this further, particularly in a representative non-White sample would be of great value. The fact that previous research has suggested that intra-racial factors play a role in jury decision making (Sommers \& Elsworth, 2000), where same race is favoured, suggests that intra- and interracial 
biases may be contextual, so in the case of a jury the task is a decision of guilt, in this study it is an attribution of a behaviour.

Unlike previous findings the results of this study suggest that the behaviour of a female protagonist is more concerning than the same behaviour by a male. Again, the differences are very small so need to be considered with caution, however this may be less to do with gender per se and more the impact of race. This is because previous studies that find the opposite gender effect, or none at all, have not included race in their designs and this is the one obvious difference. It may be possible to explore this through a replication of this study but additionally asking participants which factors they considered important in their decision making, or to design a study with a qualitative section that allowed for exploration of the factors that influenced individual decisions. The impact of participant gender cannot be discounted, as the participant sample was predominantly female this may be another example of Turner's (1982) Referent Informational Influence whereby females become more critical and rejecting of other females' behaviour when it does not appear to fit with what are considered to be female norms. A study that examined women's views of acceptable female behaviour may shed some light on this area. Work that has looked at male and female views of what is acceptable in dating behaviour suggests that views have changed little in the last 50 years (Laner \& Ventrone, 2000) and it is plausible that we use these dating scripts to make judgements about the nature of others' behaviour and if it fits with male and female gender norms.

The data regarding motivations for stalking could be construed as an implicit examination of racism or sexism. The fact that there were no such patterns and that almost entirely the motivations assigned to the behaviour were not malign is interesting. It is important to examine how attributed motivations might change if the severity of the behaviour increases as, to always assign benign motivations to intrusive behaviour may suggest a lack of understanding or awareness of risk or of the real nature of the behaviour. In this case, as the described behaviour was low level it is perhaps more appropriate that participants are not immediately assuming the worst. Interestingly though, the attributions of motivation may have been benign but there is still an acknowledgement that the behaviour is, to some degree, stalking, and thus outside of what might be considered typical behaviour between the sexes.

One might argue that these findings are compromised by the low level of stalking in the vignettes. Although possibly true there are two issues to consider. The first is that pilot studies demonstrate that a fairly mild escalation 
in the described behaviour results in ceiling effects so nothing can be examined. The second is that to impact upon stalking it is important to understand the early phases of the process as this is the point where intervention is most likely to prevent harm to targets and may well be more able to provide suitable support for the protagonists, whether that is through the criminal justice system or some other form of action.

Overall the results reported herein provide a useful first account of how race may play a role in heterosexual examples of low level stalking and suggest that further work should examine where else along the criminal justice pathway race may influence decision making. They also provide identification that previous research may have presented a somewhat over-simplified view of responses to stalking where racism and stalking have not been considered, as both gender and race within the stimuli and the participants are likely to have impacted the results.

\section{CONCLUSIONS}

The results from this study suggest that racism and sexism do play a part in the responses people provide when required to make judgements about stalking-like behaviour, which supports research concerned with other forms of offence-related behaviour, such as rape. The data did not allow for the extent of that contribution to be safely tested, but it does point to a crucial research agenda for the future to allow us to understand the extent to which people perceive stalking behaviour as more-or-less serious, impactful, requiring intervention and so forth and possibly avenues to combat bias that may leave targets feeling unsupported. Intra-racial stalking-like behaviour and stalkinglike behaviour from a female protagonist (in heterosexual pairings) were considered stronger examples of stalking. Clearly any form of decision-making bias is important, perhaps particularly in criminal justice settings and where one is assessing risk to self or others and it is important to examine both further in relation to stalking to determine if there is an applied need to counter these biases so that individuals can make suitably informed decisions to protect themselves and the criminal justice system is responding appropriately to offending behaviour. The extent to which attribution of motivation is influenced by race and gender, and how this attribution contributes to target behaviour, is crucial to understanding the reporting of offending behaviour and decisions regarding risk, particularly where rates of reporting are low and professional responses may be unreliable. 


\section{REFERENCES}

Aosved, A.C., Long, P.J., \& Voller, E.K. (2009). Measuring sexism, racism, sexual prejudice, ageism, classism, and religious intolerance: The intolerant schema measure. Journal of Applied Social Psychology, 39(10), 2321-2354. DOI: $10.1111 /$ j.1559-1816.2009.00528.x

Baum, K., Catalano, S., Rand, M., \& Rose, K. (2009). Stalking Victimization in the United States. Washington, D.C.: U.S. Department of Justice.

Bjerregaard, B. (2002). An empirical study of stalking victimization. In K.E. Davis, I.H. Frieze, \& R.D. Maiuro (Eds.) Stalking: Perspectives on victims and perpetrators. NY: Springer Publishing Company (pp. 112-137).

Black, M.C., Basile, K.C., Breiding, M.J., Smith, S.G., Walters, M.L., Merrick, M.T., Chen, J., \& Stevens, M.R. (2011). The National Intimate Partner and Sexual Violence Survey (NISVS): 2010 Summary Report. Atlanta, GA: National Center for Injury Prevention and Control, Centers for Disease Control and Prevention.

BPS (2017). Ethics Guidelines for Internet-mediated Research. https://www.bps.org.uk/sites/www.bps.org.uk/files/ Policy/Policy\%20-\%20Files/Ethics\%20Guidelines\%20for\%20Internet-mediated\%20Research\%20\%282017\%29 .pdf

Brewer, M. B. (1999). The psychology of prejudice: Ingroup love or outgroup hate. Journal of Social Issues, 55, $429-444$.

Camilli, G. \& Hopkins, K.D. (1978). Applicability of Chi-Square to 2 x 2 Contingency Tables with Small Expected Cell Frequencies, Psychological Bulletin, 85(1), 163-167.

Cass, A. I., \& Mallicoat, S. L. (2015). College Student Perceptions of Victim Action: Will Targets of Stalking Report to Police? American Journal of Criminal Justice, 40(2), 250-269.

Correll, J., Park, B., Wittenbrink, B. \& Judd, C.M. (2002). The police officer's dilemma: Using ethnicity to disambiguate potentially threatening individuals. Journal of Personality and Social Psychology, 83(6), 1314-1329. 
Correll, J., Park, B., Judd, C.M., Wittenbrink, B., Sadler, M.S. \& Keesee, T. (2007). Across the thin blue line: Police officers and racial bias in the decision to shoot. Journal of Personality and Social Psychology, 92(6), 10061023.

Day, K. (1999). Embassies and sanctuaries: women's experiences of race and fear in public space. Environment and Planning D, 17, 307-328.

Dietz, N.A., \& Martin, P.Y. (2007). Women who are stalked: Questioning the fear standard. Violence against Women, 13(7), 750-776.

Dixon, J.A., Mahoney, B., \& Cocks, R. (2002). Accents of guilt? Effects of regional accent, race, and crime type on attributions of guilt. Journal of Language and Social Psychology, 21(2), 162-168.

Duff, S.C. \& Scott, A.J. (2013). Understanding perceptions of stalking: The impact of additional contextual information regarding the breakdown of relationships. Journal of Criminal Psychology, 3(2), 136-144. DOI: 10.1108/JCP-09-2012-0005

Duff, S.C., Birchall, J., Bisbee, E., Wheatcroft, J., Gavin, J., \& Scott, A.J. (in press). Prior relationship, relationship breakdown, and group decisions in the attribution of cases of stalking.

Faul, F., Erdfelder, E., Lang, A.-G., \& Buchner, A. (2007). G*Power 3: A flexible statistical power analysis program for the social, behavioral, and biomedical sciences. Behavior Research Methods, 39, 175-191.

George, W.H. \& Martinez, L.J. (2002). Victim blaming in rape: Effects of victim and perpetrator race, type of rape, and participant racism. Psychology of Women Quarterly, 26, 110-119.

Hacker, A. (1995). Two Nations: Black and White, Separate, Hostile and Unequal. 2nd Ed. NY: Ballantine Books. 
Hurwitz, J. \& Peffley, M. (1997). Public perceptions of race and crime: The role of racial stereotypes. American Journal of Political Science, 41(2), 375-401.

Kinkade, P., Burns, R. \& Fuentes, A.I (2005). Criminalizing attractions: Perceptions of stalking and the stalker. Crime \& Delinquency, 51(1), 3-25. DOI: 10.1177/0011128703262462

Laner, M.R. \& Ventrone, N.A. (2000). Dating scripts revisited. Journal of Family Issues, 21(4), 488-500.

Lantz, B., Gladfelter, A.S., \& Ruback, R.B. (2017). Stereotypical hate crimes and criminal justice processing: A multi-dataset comparison of bias crime arrest patterns by offender and victim race. Justice Quarterly, 1-32. DOI: $10.1080 / 07418825.2017 .1399211$

Lyndon, A. E., Sinclair, H. C., MacArthur, J., Fay, B., Ratajack, E., \& Collier, K. E. (2012). An introduction to issues of gender in stalking research. Sex Roles, 66, 299-310. DOI: 10.1007/s11199-011-0106-2

MacKenzie, R., McEwan, T., Pathé, M., James, D., Ogloff, J., \& Mullen, P. (2009). Stalking Risk Profile: Guidelines for the Assessment and Management of Stalkers. Melbourne: StalkInc \& Center for Forensic Behavioral Science, Monash University.

Madriz, E.I. (1997). Images of criminals and victims: A study on women's fear and social control. Gender and Society, 11(3), 342-356.

Mays, V. M., Johnson, D., Coles, C. N., Gellene, D., \& Cochran, S. D. (2013). Using the Science of Psychology to Target Perpetrators of Racism and Race-Based Discrimination For Intervention Efforts: Preventing Another Trayvon Martin Tragedy. Journal for Social Action in Counseling and Psychology, 5(1), 11-36.

Meloy, J.R. (2013). Stalking. In J.A. Siegel \& P.J. Saukko (eds.) Encyclopedia of Forensic Sciences, Second Edition, vol. 1, pp. 202-205. Waltham: Academic Press. 
van de Mortel, T.F. (2008). Faking it: Social desirability responses in self-report research. Australian Journal of Advanced Nursing, 25(4), 40-48.

ONS (2017). https://www.ons.gov.uk/employmentandlabourmarket/peopleinwork/ employmentandemployeetypes/articles/graduatesintheuklabourmarket/2017\#steady-increase-in-the-number-ofgraduates-in-the-uk-over-the-past-decade. Retrieved $1^{\text {st }}$ May 2018.

Payne, B. K. (2001). Prejudice and perception: The role of automatic and controlled processes in misperceiving a weapon. Journal of Personality and Social Psychology, 18(2), 181-192. DOI: 10.1037//0022-3514.81.2.181

Pearce, A. \& Easteal, P. (1999). The "domestic" in stalking: policing domestic stalking in the Australian Capital Territory. Alternative Law Journal, 24, 165-174.

Podaná, Z., \& Imríšková, R. (2016). Victims’ responses to stalking: An examination of fear levels and coping strategies. Journal of Interpersonal Violence, 31, 792-809. DOI: 0.1177/0886260514556764

Quade, D. (1967). Rank analysis of covariance. Journal of the American Statistical Association, 62(320), 11871200. Stable URL: https://www.jstor.org/stable/2283769

Rosenfeld, B. (2004). Violence risk factors in stalking and obsessional harassment: A review and preliminary metaanalysis. Criminal Justice and Behavior, 31(1), 9-36.

Scott, A.J., Duff, S. C., Sheridan, L., \& Rajakaruna, N., (2018). The Influence of Contextual Information regarding the Breakdown of Relationships and Perpetrator-Target Sex Composition on Perceptions of Relational Stalking. Psychology, Crime \& Law, 12, 1-36.

Scott, A.J. \& Gavin, J. (2011). The influence of prior relationship on perceptions of stalking in mock jury deliberations. Forensic Update, 104, 32-37. 
Scott, A. J., Nixon, K., \& Sheridan, L. (2013). The influence of prior relationship on perceptions of stalking. A comparison of laypersons, nonspecialist police officers, and specialist police officers. Criminal Justice and Behavior, 40, 1434-1448. DOI: http://dx.doi.org/10.1177/0093854813494183

Scott, A.J., Rajakaruna, N., Sheridan, L., \& Gavin, J. (2015). International Perceptions of Relational Stalking: The Influence of Prior Relationship, Perpetrator Sex, Target Sex, and Participant Sex. Journal of Interpersonal Violence, 30(18) 3308-3323. DOI: 10.1177/0886260514555012

Scott, A.J. \& Tse, P.K. (2011). An exploratory study of the influence of perpetrator and victim sex on perceptions of stalking. Forensic Update, 103, 9-13.

Sheridan, L., Blaauw, E., \& Davies, G.M. (2003). Stalking: Knowns and unknowns. Trauma, Violence, \& Abuse, 4(2), 148-162. DOI: $10.1177 / 1524838002250766$

Sheridan, L. P., North, A. C., \& Scott, A. J. (2014). Experiences of stalking in same-sex and opposite-sex contexts. Violence and Victims, 29(6), 1014-1028

Sheridan, L., \& Scott, A. J. (2010). Perceptions of harm: Verbal versus physical abuse in stalking scenarios. Criminal Justice and Behavior, 37(4), 400-416.

Sommers, S.R. \& Elsworth, P.C. (2000). Race in the courtroom: Perceptions of guilt and dispositional attributions. Personality and Social Psychology Bulletin, 26(11), 1367-1379.

Steffensmeier, D., Ulmer, J., \& Kramer, J. (1998). The interaction of race, gender, and age in criminal sentencing: The punishment cost of being young, Black, and male. Criminology, 36(4), 763-798. DOI: 10.1111/j.17459125.1998.tb01265.x

Strand, S. \& McEwan, T. E. (2012). Violence among female stalkers $M$ 545-555. 
Tajfel, H. (1981). Human groups and social categories. Cambridge: Cambridge University Press.

Thomas, C. (2010). Are juries fair? Ministry of Justice Research Series 1/10.

Turner, J.C. (1982). Towards a cognitive redefinition of the social group. In H. Tajfel (Ed.). Social Identity and Intergroup Relations. Cambridge: Cambridge University Press.

Ugwuegbu, D.C.E. (1979). Racial and evidential factors in juror attribution of legal responsibility. Journal of Experimental Social Psychology, 15, 133-146.

Valentine, G. (1989). The geography of women's fear. Area, 21, 385-390.

Weller, M., Hope, L., \& Sheridan, L. (2013). Police and public perceptions of stalking: the role of prior victimoffender relationship. Journal of Interpersonal Violence, 28, 320-339. DOI: 10.1177/0886260512454718 
Figure 1. Examples of faces used as stimuli, the Black male face, and the White female face.
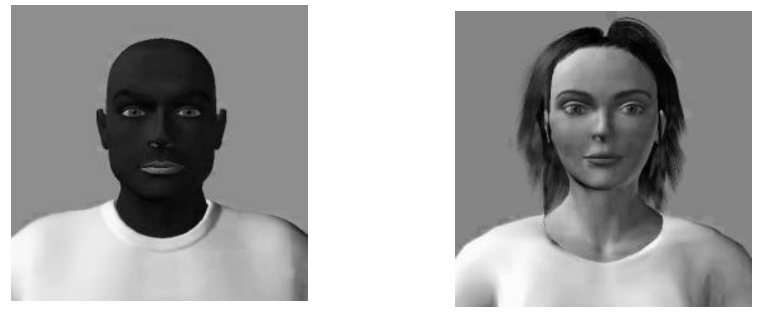
Table 1 Participants per group and means for attributions of stalking and means of racism and sexism scores.

\begin{tabular}{|r|c|c|c|c|}
\hline & & Behaviour & & \\
\hline Group & $\mathbf{N}$ & is stalking & Racism & Sexism \\
\hline $\mathbf{1}$ & 62 & 7.1 & 17.4 & 12.7 \\
\hline $\mathbf{2}$ & 70 & 5.5 & 16.2 & 12.6 \\
\hline $\mathbf{3}$ & 78 & 5.9 & 17.2 & 12.4 \\
\hline $\mathbf{4}$ & 68 & 6.2 & 17.6 & 13.2 \\
\hline $\mathbf{5}$ & 88 & 6.6 & 18.9 & 12.9 \\
\hline $\mathbf{6}$ & 76 & 6.3 & 17.2 & 12.4 \\
\hline $\mathbf{7}$ & 62 & 6.5 & 17.4 & 13.0 \\
\hline $\mathbf{8}$ & 96 & 5.8 & 17.5 & 12.3 \\
\hline
\end{tabular}


Table 2 Number of motivations identified by condition

\begin{tabular}{|c|c|c|c|c|}
\hline \multirow[t]{2}{*}{ Motivation } & \multicolumn{4}{|c|}{$\begin{array}{c}\text { Condition } \\
\text { protagonist race and gender : target race and gender }\end{array}$} \\
\hline & 1 & 2 & 3 & 4 \\
\hline Male protagonist - Female Target & WM:WF & WM:BF & BM:WF & BM:BF \\
\hline At some time in the recent past Sarah humiliated Michael & 2 & 0 & 0 & 0 \\
\hline Michael and Sarah were in a relationship and Michael is trying to win her back & 2 & 2 & 8 & 8 \\
\hline Michael is lonely and wants to have a relationship with Sarah, who he thinks likes him & 26 & 24 & 36 & 32 \\
\hline Michael is not stalking Sarah & 8 & 12 & 12 & 6 \\
\hline Michael wants a date with Sarah & 24 & 32 & 20 & 22 \\
\hline Michael both enjoys making Sarah feel uncomfortable and plans to assault her & 0 & 0 & 2 & 0 \\
\hline & 5 & 6 & 7 & 8 \\
\hline Female protagonist - Male Target & WF:WM & BF:WM & WF:BM & BF:BM \\
\hline At some time in the recent past Michael humiliated Sarah & 2 & 0 & 0 & 0 \\
\hline Sarah and Michael were in a relationship and Sarah is trying to win him back & 14 & 4 & 10 & 9 \\
\hline Sarah is lonely and wants to have a relationship with Michael, who she thinks likes her & 44 & 40 & 38 & 45 \\
\hline Sarah is not stalking Michael & 6 & 12 & 4 & 18 \\
\hline Sarah wants a date with Michael & 20 & 22 & 10 & 29 \\
\hline Sarah both enjoys making Michael feel uncomfortable and plans to assault him & 2 & 0 & 0 & 0 \\
\hline
\end{tabular}

